\title{
Quasi-6-day waves in the mesosphere and lower thermosphere region and their possible coupling with the $\mathrm{QBO}$ and solar 27-day rotation
}

\author{
JianYuan Wang ${ }^{1,2}$, Wen Yi ${ }^{1,2}$, TingDi Chen ${ }^{1,2,3^{*}}$, and XiangHui Xue ${ }^{1,2,3,4}$ \\ ${ }^{1}$ Chinese Academy of Sciences Key Laboratory of Geospace Environment, Department of Geophysics and Planetary Sciences, University of Science and \\ Technology of China, Hefei 230026, China; \\ ${ }^{2}$ Mengcheng National Geophysical Observatory, School of Earth and Space Sciences, University of Science and Technology of China, Hefei 230026, China; \\ ${ }^{3}$ Chinese Academy of Sciences Center for Excellence in Comparative Planetology, Hefei 230026, China; \\ ${ }^{4}$ Synergetic Innovation Center of Quantum Information and Quantum Physics, University of Science and Technology of China, Hefei 230026, China

\section{Key Points:} \\ - Features of seasonal variations in the 6DWs are significant, and these seasonal features are slightly different in the mid-low latitudes \\ - The annual oscillations of the 6DWs in the mid-low latitudes are modulated by the quasi-biennial oscillation in the diurnal tide, \\ resulting in seasonal features that are different from those at other latitudes \\ - The 6DW amplitudes at mid-high latitudes has a significant 27-day solar rotation variation.
}

Citation: Wang, J. Y., Yi, W., Chen, T. D., and Xue, X. H. (2020). Quasi-6-day waves in the mesosphere and lower thermosphere region and their possible coupling with the QBO and solar 27-day rotation. Earth Planet. Phys., 4(3), 285-295. http://doi.org/10.26464/epp2020024

\begin{abstract}
By using atmospheric wind data in the mesopause and lower thermosphere (MLT) region, features of seasonal variations in the quasi-6-day wave (6DW) at different latitudes are analyzed, and modulation of the 6DW by the diurnal tide and solar 27-day period is discussed. The data used in the analysis are extracted from a wind dataset collected by a meteor radar chain from December 2008 to November 2017. The meteor radar chain includes four stations, in Mohe, Beijing, Wuhan, and Sanya. Features of seasonal variations in the $6 \mathrm{DW}$ indicate that in summer the 6DW is usually strongest during July and August, followed by stronger variations in January and April. At certain altitudes over Wuhan and Sanya, the 6DW is slightly different in different years and altitudes. In our analysis of seasonal variations in the $6 \mathrm{DW}$, we find that it is generally affected by annual oscillations and semiannual oscillations. The annual oscillations of the 6DW in the mid-low latitudes are modulated by the quasibiennial oscillation in the diurnal tide, resulting in seasonal features that are different from those at other latitudes. In addition, the 6DW amplitude at mid-high latitudes has a significant 27-day solar rotation variation, which was prominent in 2016.
\end{abstract}

Keywords: quasi-6-day wave; meteor radar winds; seasonal variations; quasibiennial oscillation; tides; 27-day variation

\section{Introduction}

Planetary waves, also known as Rossby waves, are global-scale atmospheric waves. These waves are thought to be generated by the dynamic and thermal effects of the Earth's rotation. Planetary waves are responsible for the longer-term atmospheric variations in the upper atmosphere, such as the quasibiennial oscillation (QBO) in the lower latitude area (Garcia et al., 2005; Liu HL et al., 2010; Salby, 1984).

The westward propagating quasi-6-day wave (6DW) is one of these planetary waves, with period from 4 to 7 days and zonal wavenumber 1 (Riggin et al., 2006; Wu DL et al., 1994). The 6DW is one of the most significant planetary waves in the mesopause and

Correspondence to: T. D. Chen, ctd@ustc.edu.cn

Received 17 DEC 2019; Accepted 30 DEC 2019.

Accepted article online 28 FEB 2020.

(C)2020 by Earth and Planetary Physics. lower thermosphere $(\mathrm{MLT})$ region. In the MLT region, planetary waves with periods from 4 to 7 days are often observed in two different periods, at approximately 5 days and approximately 6.5 days (Belova et al., 2008). Wu DL et al. (1994) reported the 5-day wave in the wind dataset measured by the High Resolution Doppler Imager (HRDI) over the Upper Atmosphere Research Satellite (UARS) and suggested that these 5-day to 7-day planetary waves may be the $(1,1)$ Rossby normal mode, which is consistent with research carried out by Salby (1981). However, it is proposed that the Doppler shift could cause a period change of only 0.5 days (Geisler and Dickinson, 1976), and the 6DW may be a baroclinic/barotropic instability in the MLT region (Lieberman et al., 2003). Moreover, Geisler and Dickinson (1976) suggested that the wave amplitudes are amplified in the MLT region in the westward zonal mean winds, but the intensity of the 5-day wave normal modes decays with altitudes increasing away from the source and stratosphere without continuous forcing (Andrews et al., 
1987). Thus, in this study, planetary waves with periods from 4 to 7 days in the MLT region are considered to be 6DWs.

Over the past decades, the 6-day planetary wave has been extensively studied with both observations and numerical simulations (Forbes and Zhang XL, 2017; Gan Q et al., 2016; Gu SY et al., 2018; Lieberman et al., 2003; Liu HL et al., 2004; Miyoshi and Hirooka, 1999; Talaat et al., 2001; Wu DL et al., 1994). Talaat et al. (2001) used the HRDI dataset to study seasonal variations in the quasi-6day wave, and this dataset showed that the 6-day wave at the mesosphere peaked before and after the equinox, which is consistent with simulation results by Liu HL et al. (2004). Using the National Center for Environmental Prediction (NCEP) reanalysis data, Miyoshi and Hirooka (2003) studied the quasibiennial oscillation (QBO) of the 5-day wave amplitude in the stratosphere, and described the mechanism underlying the relationship between the QBO in the 5-day wave amplitude and in the equatorial zonal wind variation. Moreover, it has been proven that the vertical wavelengths of 6.5-day waves are considerably larger at approximately $60-80 \mathrm{~km}$, which could propagate from the lower to upper atmosphere (Forbes, 2000). Previous 6-day wave studies mainly used satellite datasets and model simulations, but groundbased and long-term observations are very limited. Using the MF radar systems at Urbana $\left(40.1^{\circ} \mathrm{N}, 87.8^{\circ} \mathrm{W}\right)$, Saskatoon $\left(52.1^{\circ} \mathrm{N}\right.$, $\left.106.6^{\circ} \mathrm{W}\right)$ and Durham $\left(43.1^{\circ} \mathrm{N}, 70.9^{\circ} \mathrm{W}\right)$ during August and September 1993, Meyer and Forbes (1997) analyzed the origin and characteristics of a 6-7 day westward propagating planetary wave. Jiang $G$ et al. (2008b) presented the latitudinal feature and vertical structure of the 6.5-day wave observed by six groundbased radar systems in equatorial and midlatitude regions. However, the radar data are limited to observations from April to May 2003. Gong Y et al. (2018) reported interannual and seasonal variations in quasi-5-day waves and the mechanism by which the 2013 SSW led to 5DW amplification by using neutral wind data from a meteor radar chain. These studies revealed that the 6-day wave is evident in the MLT region, but its characteristics and modulation by some other variations have not been comprehensively reported or analyzed.

In this study, we present observations of 6DWs in the horizontal winds by a meteor radar chain over 4 meteor radars in the period from December 4, 2008 to November 26, 2017. We investigate preliminarily $6 \mathrm{DW}$ variations on different time scales. The observational instruments and data processing methods are given in Section 2. The analysis results of the 6DWs are presented in Section 3. In Section 4 we discuss extensively the latitudinal, interannual, and short-term variations in 6DW amplitudes in the MLT region. Finally, our conclusions are summarized in Section 5.

\section{Data and Methods}

In this study, horizontal wind data from four meteor radars located at Mohe $\left(53.5^{\circ} \mathrm{N}, 122.3^{\circ} \mathrm{E}\right)$, Beijing $\left(40.3^{\circ} \mathrm{N}, 116.2^{\circ} \mathrm{E}\right)$, Wuhan $\left(30.5^{\circ} \mathrm{N}, 114.2^{\circ} \mathrm{E}\right)$ and Sanya $\left(18.4^{\circ} \mathrm{N}, 109.6^{\circ} \mathrm{E}\right)$, called $\mathrm{MH}, \mathrm{BJ}, \mathrm{WH}$ and SY, respectively, were used. Table 1 summarizes the operating frequencies, geographic coordinates, and observational time spans for the meteor radar dataset used in this study (Li GZ et al., 2018). These meteor radars are ATRAD meteor detection radar (MDR) series (Holdsworth et al., 2004; Yi W et al., 2019) and all belong to the Institute of Geology and Geophysics, Chinese Academy of Sciences (IGGCAS), which is part of the Chinese Meridian Project and STERN (the Solar-Terrestrial Environment Research Network). Figure 1 shows the geographic locations of these four meteor radars.

The radar system transmitted radio waves and coherently detected their reflections from meteor trails. Distances to reflecting material can be obtained by the time intervals between transmission and detection, and the azimuth or elevation angle measurement is calculated from the phase displacement (Franke et al., 2005; Holdsworth et al., 2004). Assuming that the vertical wind is negligible, the horizontal wind can be determined by the Doppler shift, following the algorithms in Hocking et al. (2001).

All four radars are used to measure horizontal winds from 70 to $110 \mathrm{~km}$. Temporal and altitudinal resolutions are 1 hour and $2 \mathrm{~km}$, respectively. However, due to the smaller number of meteors at 70-80 km and 100-110 km, horizontal wind data at these altitudes are extremely limited. Therefore, only horizontal wind data at $80-100 \mathrm{~km}$ are analyzed in this study.

The power spectral density analysis provides an overview of the dominant oscillation modes in a given neutral wind component. Due to uneven temporal sampling, Lomb-Scargle (LS) analysis (Lomb, 1976; Scargle, 1982) is applied in this study to derive the periodograms of neutral winds. Note that the periodicities between 4 and 7 days are considered to be the 6DWs in this study.

\section{Results}

A spectral analysis of the horizontal winds described above reveals that there is a wave with a period close to 6 days. As an example, Figure 2 shows the moving Lomb-Scargle periodogram of the zonal wind at $90 \mathrm{~km}$ over Beijing during the observational period from January 1, 2012 to March 1, 2012. This periodogram is obtained from daily mean zonal wind using a 12-day sliding window with a step of one day. It can be seen from the spectrum periodogram that the main period of the fluctuation occurs between 4 days and 7 days, the period near 6 days ( 6.3 days in the figure) being the most significant.

Table 1. Geographic locations, working frequencies, and observational time periods of the meteor radars used in this study.

\begin{tabular}{|c|c|c|c|}
\hline Meteor radar & Geographic locations & Frequency & Data used in this study \\
\hline Beijing (BJ) & $40.3^{\circ} \mathrm{N}, 116.2^{\circ} \mathrm{E}$ & $38.9 \mathrm{MHz}$ & 2008/12/4-2017/11/26 \\
\hline Wuhan (WH) & $30.5^{\circ} \mathrm{N}, 114.2^{\circ} \mathrm{E}$ & $38.9 \mathrm{MHz}$ & 2010/9/22-2017/11/26 \\
\hline Sanya (SY) & $18.4^{\circ} \mathrm{N}, 109.6^{\circ} \mathrm{E}$ & $47.5 \mathrm{MHz}$ & 2009/1/25-2014/4/13 \\
\hline
\end{tabular}




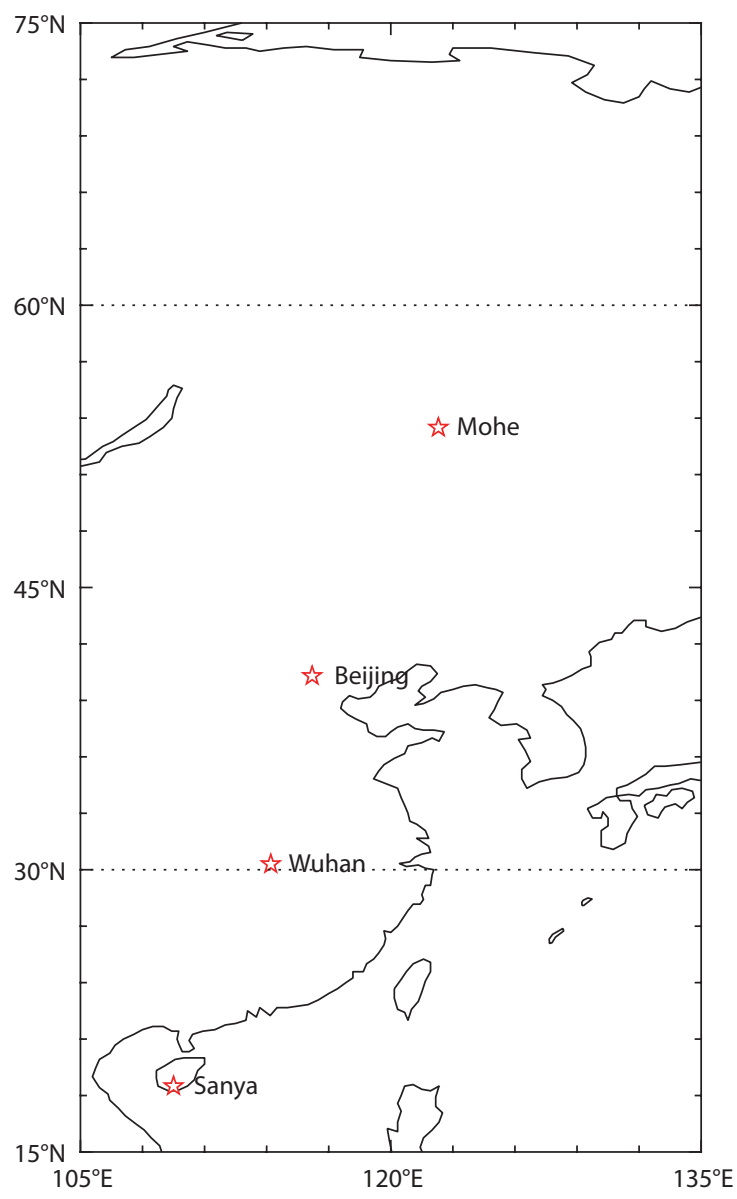

Figure 1. The locations of the 4 meteor radar stations used in this study.

LS amplitude periodogram (m/s) near 6-day period over Beijing

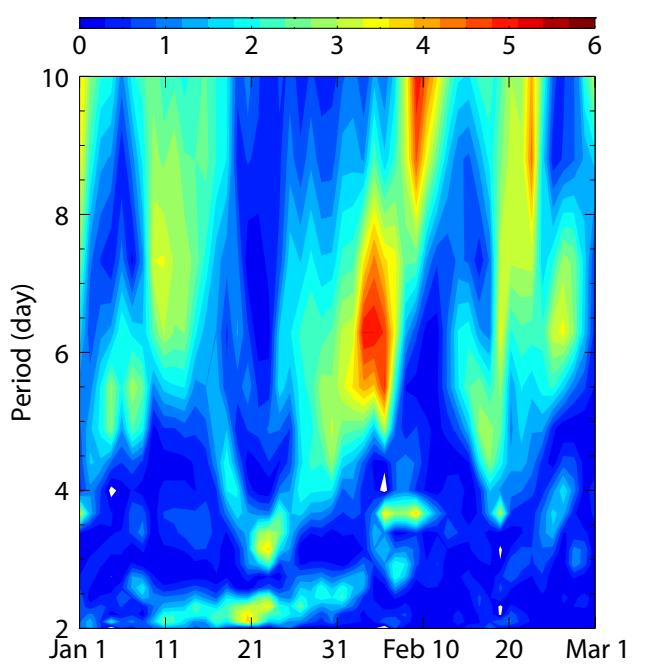

Figure 2. Moving Lomb-Scargle periodogram of the zonal wind over the Beijing station near the 6-day period in the time period from January 1 to March 1, 2012. The results with a 95\% confidence level are larger than $1.8 \mathrm{~m} / \mathrm{s}$.

Since the meteor radar observation process may not be turned on for a certain period of time or the number of meteors at a certain height may be insufficient, the horizontal wind data may be dis- continuous for a long time span. To approximate daily mean winds, the horizontal wind data are mathematically processed here. Because the wave period we are interested in is approximately 6 days, the horizontal wind is averaged daily; if the number of effective data points is less than 12 in one day at one altitude, no average is performed at this point, and the winds at this altitude on this day are marked as Not a Number (NAN).

To investigate these waves further, it is necessary to obtain the 6day wave amplitudes of the horizontal wind. In this study, we applied a least squares fitting method to estimate the 6-day wave amplitudes from the neutral winds dataset. According to the LS periodogram, the most intense oscillation mode between 4 and 7 days was chosen as the 6-day wave period. Then, the least squares fitting is used for the horizontal wind data from December 2008 to November 2017. The fitting simultaneously extracts amplitudes of the quasi-6-day wave, quasi-2-day wave and 10-day mean wind from the daily mean horizontal wind data, which are observed as the significant variation in Figure 2.

To obtain the 6DW amplitudes, we chose an 18-day sliding window for the least squares fitting. The screening conditions for the fitting are as follows: first, if the effective data in the window are less than $1 / 2$, no fitting is performed; second, if the effective data in the window occupy less than $2 / 3$ of their phase, fitting is not allowed; for other situations, these 18-day wind data could be fitted. As a result, Figure 3 shows the 6DW amplitude of the zonal wind and meridional wind filtering of four stations on the meteor radar chain during the time period from December 4, 2008 to November 26, 2017. The analysis in Figure 3 shows that the 6DW is most intense during January and February in winter and July and August in late summer. For example, in the late summer of 2011 , the 6 DW of the zonal wind reached $18 \mathrm{~m} / \mathrm{s}$ over Beijing, and in the early spring of 2012 , it exceeded $14 \mathrm{~m} / \mathrm{s}$ in the meridional wind over Sanya.

\section{Discussion}

\subsection{Seasonal Variations in 6DW Amplitudes}

To show more clearly the seasonal variation in 6DW, Figure 4 shows the seasonal features of the 6DW amplitude of zonal wind and meridional wind at four stations on the meteor radar chain during the time interval from December 4, 2008 to November 26, 2017. It can be seen that at Mohe station, the 6DW amplitude of the zonal wind reached its strongest level in July and at the vernal equinox, and that the range of the meridional direction was greatest in August. At the Beijing station, the 6DW amplitude of the zonal wind was significant in February and September, near the autumnal equinox; the meridional wind peaked at its strongest in March and July. At the Sanya station, the 6DW amplitude of the zonal wind was strongest from July to September and in January, and the range of the meridian was greatest at the autumnal equinox and in February over $92 \mathrm{~km}$. However, at the Wuhan station, only the amplitudes above $95 \mathrm{~km}$ in the zonal component demonstrated significant seasonal variations; there, they were strongest in February to April; the seasonal features are weaker in other components or at other heights; especially lacking are the summer features observed elsewhere. 

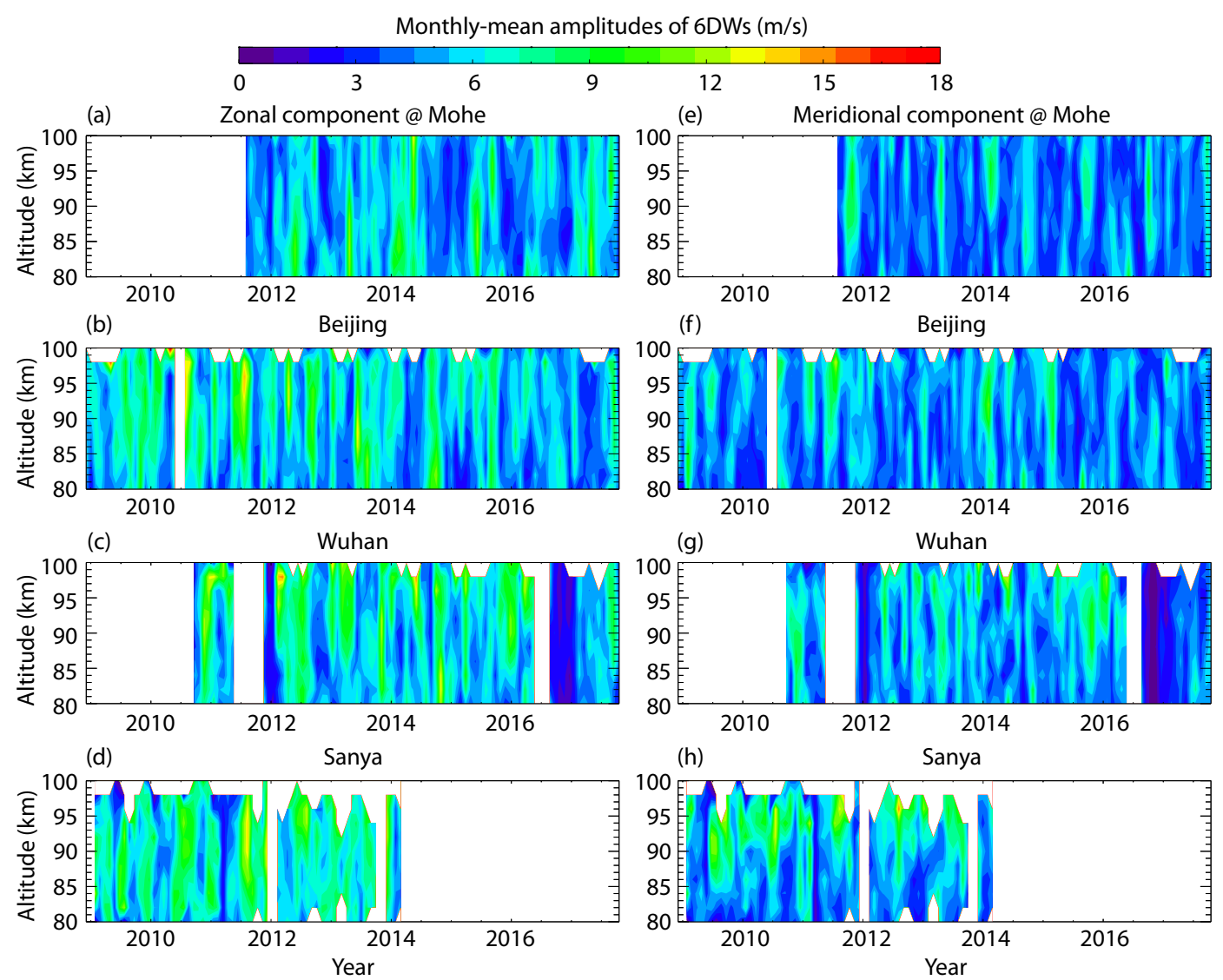

Figure 3. Altitude-year-intensity plot of the monthly-mean amplitudes of 6DWs in the zonal and meridional components, from December 2008 to November 2017 over the Mohe, Beijing, Wuhan, and Sanya stations (from $80 \mathrm{~km}$ to $100 \mathrm{~km}$ ).

Through the above seasonal features, the seasonal features over Mohe are similar to the results of the model simulation. The 6DW amplitudes in the zonal component reach their maximum near the vernal equinox and decay to their minimum near solstices ( $\mathrm{Ji}$ ang $G$ et al., 2008a; Lieberman et al., 2003). In Beijing and Sanya, 6DW amplitudes are strongest in the summer, August to September, and second strongest near February, which is similar to the result of the 1993 TIME-GCM simulation at $40^{\circ} \mathrm{N}$ and $22.5^{\circ} \mathrm{N}$ by Liu $\mathrm{HL}$ et al. (2004). It has been proven that the reason 6DW amplitudes in summer are stronger than in winter is that the horizontal wind is weaker near the time of the winter solstice; thus, the wind can hinder wave propagation, and the wind curvature is large in the summer mesosphere, and the wave may be amplified by instability (Liu HL et al., 2004). However, the intensive 6DW amplitudes observed over Sanya near January were not found in that simulation, so the phenomenon may be due to modulation of some long-period oscillations, such as the QBO, which will be discussed later. In addition, since there is only one meteor radar at each latitude, the 6DW is the superposition of all wavenumber modes, which may also be one of the reasons for the inconsistency between observations and simulation.

These seasonal features reflect the variations in 6DW amplitudes over a period of one year or half a year; thus, the annual or semiannual oscillations may be intense over Mohe, Beijing, and Sanya. The interannual variations in 6DW amplitudes are discussed below to analyze the cause of the loss of seasonal features at lower altitudes over Wuhan and Sanya.

\subsection{Interannual Variations in the 6DW Amplitudes}

To reveal the interannual variations in the 6DWs, we performed an LS analysis by using all 18-day sliding window fitting results over all 4 stations. Figure 5 shows the normalized LS periodogram of the 6DW amplitudes in the zonal (left) and meridional (right) winds over $\mathrm{MH}, \mathrm{BJ}, \mathrm{WH}$, and SY. At the Mohe station, annual oscillation (AO) and ter-annual oscillation (TAO) dominated the variation in the 6DW amplitudes in the zonal wind, and semiannual oscillation (SAO) and TAO controlled the meridional wind. This TAO oscillation may be the reason that the interval of the strongest amplitudes in zonal wind over Mohe is approximately 4 months instead of 6 months, similar to Beijing or Sanya in Figure $4 a$, as well as why three intensity minima are observed in the seasonal pattern of variation in the meridional wind over Mohe. At the Beijing station, both the zonal wind and meridional wind were strongly dominated by SAO. In particular, AO was strong at the zonal wind, and there was a strong TAO at the meridional wind over the BJ Station. At the WH Station, only TAO controlled the zonal wind, and SAO controlled the meridional wind. AO and SAO dominated both the zonal and meridional winds over the SY Station.

Disregarding the Wuhan station, we observe that the horizontal wind 6DW amplitude over the other three stations appears to be controlled by either the AO or SAO. However, there is no strong 
Seasonal variation of $6 \mathrm{DW}$ amplitudes $(\mathrm{m} / \mathrm{s})$

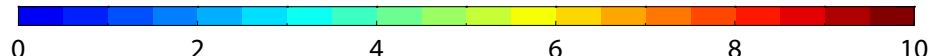

(a) Zonal component @ Mohe

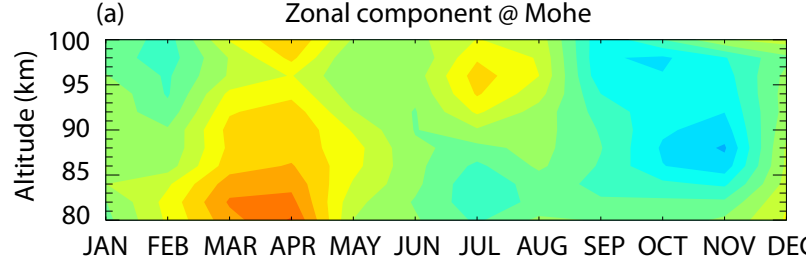

JAN FEB MAR APR MAY JUN JUL
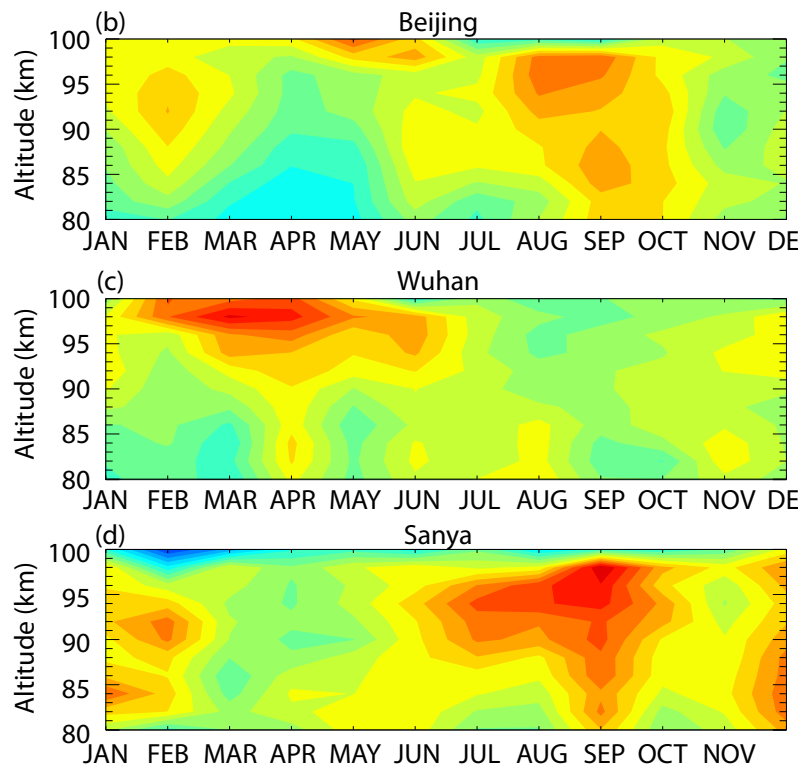

(e)

Meridional component @ Mohe

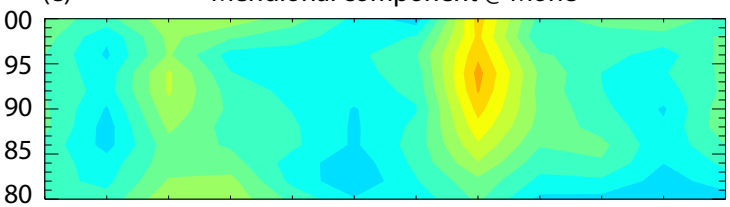

80
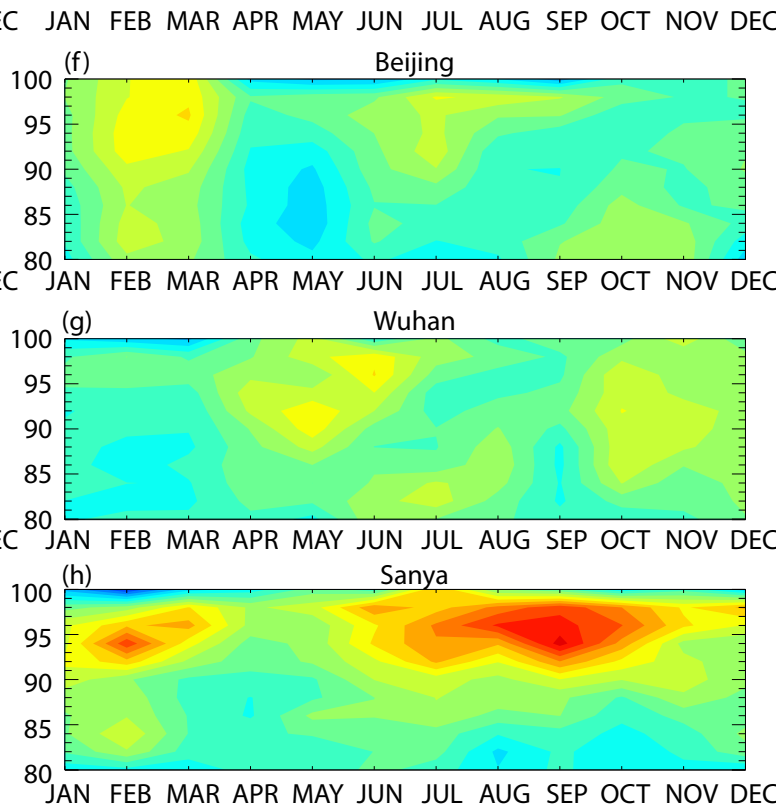

Figure 4. Monthly-mean amplitudes of the $6 \mathrm{DWs}$ in a composite-year in the zonal component (left column, a to d) and the meridional component (right column, e to h) at Mohe, Beijing, Wuhan, and Sanya.

$\mathrm{AO}$ in the meridional wind over the WH Station, so in Figure $4 \mathrm{~g}$, the 6DW amplitudes over Wuhan have no significant seasonal features. Moreover, there are some symmetrically distributed oscillation peaks near $\mathrm{AO}$. We suggest that these oscillation peaks are the result of the $A O$ being modulated by longer-period oscillations, and the modulation mechanism is determined by Equation (1):

$$
\frac{1}{\omega_{2}}=\frac{1}{\omega_{0}} \pm \frac{1}{\omega_{1}}
$$

where $\omega_{0}$ is the modulated period; $\omega_{1}$ is the longer period; and $\omega_{2}$ is the resulting period. At both the zonal and meridional winds over Wuhan station, the $\mathrm{AO}$ is modulated by a longer period of oscillation, of 21-month and 8.4-month periods, and these two periods were stronger in terms of the zonal wind. At both zonal and meridional winds over Sanya station, the AO is modulated by a longer period of oscillation of an 8.4-month period. The longer period could be obtained by the calculation of Equation (1), which is 28 months.

To verify the existence of the previous 28 -month period and the mechanism for the formation of the 21-month period and the 8.4month period, the LS spectra periodogram of the daily mean winds at the Beijing, Wuhan, and Sanya stations are given in Figure 6 . Figure 6 shows the LS spectra periodogram of the daily mean winds of the meridional and zonal winds at the Beijing, Wuhan, and Sanya stations. The figure shows that there is a strong 28-month period in the LS spectrum of the zonal wind over the Wuhan station in Figure $6 \mathrm{~b}$ and there is an intensive 28-month period in the LS spectrum of the meridional wind over the Sanya station in Figure 6f; there is no significant near-28-month period over Beijing. Moreover, this 28-month period is close to the period of the quasibiennial oscillation (QBO) in the equatorial stratosphere. However, these QBO signals in the horizontal winds cannot correspond to the 21-month and 8.4-month signals in the 6DW amplitudes, in terms of each component and altitude. For example, we noticed that the 21 -month or 8.4-month signals in the meridional 6DW amplitudes over Wuhan exist at nearly all altitudes between $80 \mathrm{~km}$ and $100 \mathrm{~km}$ in Figure $5 \mathrm{~g}$, but there is no QBO signal in the meridional winds at the same station in Figure $6 e$.

Therefore, the QBO oscillation in horizontal winds may not be the dominant factor for the shift from the $\mathrm{AO}$ of 21 -month or 8.4month period variations in 6DW amplitudes. To explain this phenomenon, the LS periodograms of diurnal tidal amplitudes in the MLT region over Beijing, Wuhan, and Sanya are given in Figure 7. As with the method of estimating the 6DW amplitudes, the tidal amplitudes are obtained by using a least squares fitting. The difference is that the tidal amplitudes are fitted by the horizontal winds with a resolution of 1 hour in a sliding window of 3 days (72 hours), and the fitting simultaneously extracts the amplitudes of the diurnal, semidiurnal, and terdiurnal tides. Figure 7 shows the 


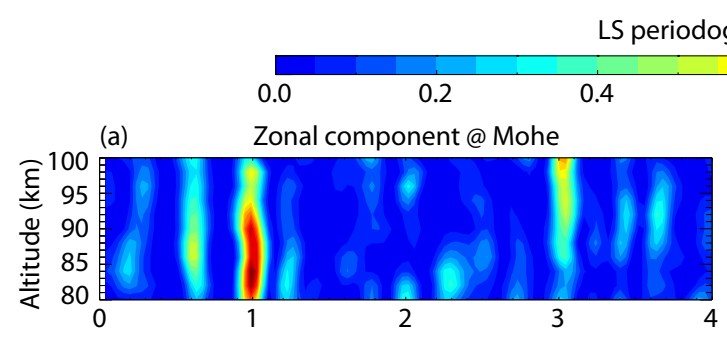

$\begin{array}{ccc}\text { gram } & & \\ 0.6 & 0.8 & 1.0\end{array}$

(b)

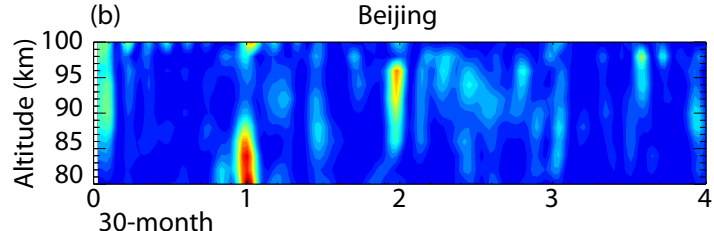

(c)

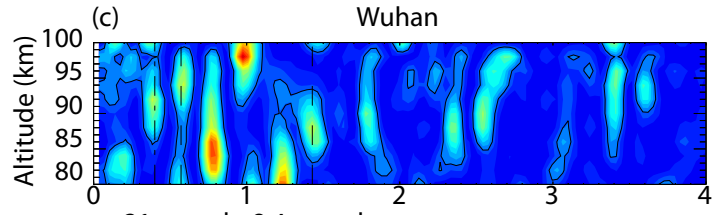

21-month 8.4-month

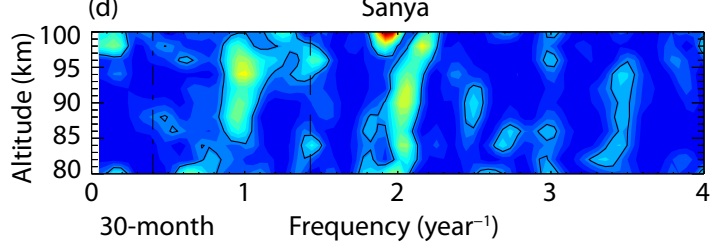

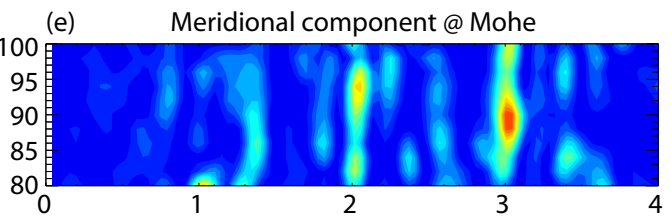

(f)

Beijing
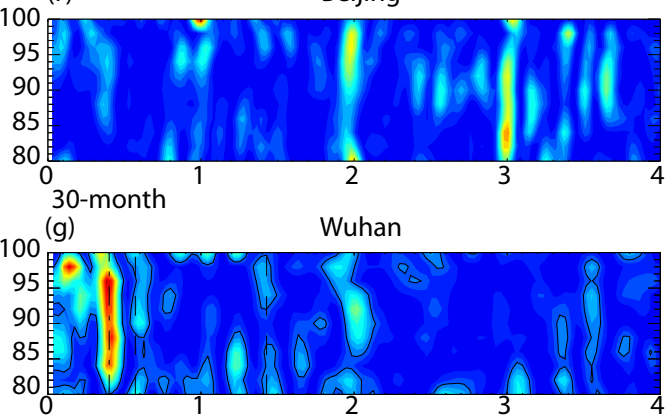

21-month 8.4-month

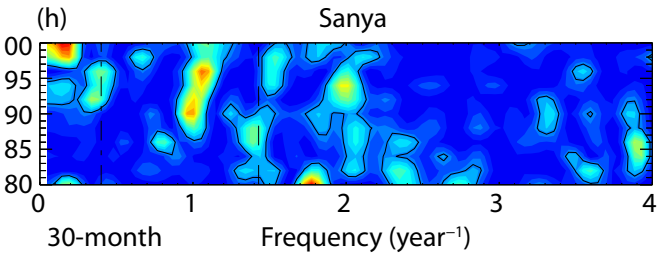

Figure 5. Normalized Lomb-Scargle periodogram of the 6DW amplitudes in the zonal component (left column, a to d) and the meridional component (right column, e to h) at Mohe, Beijing, Wuhan, and Sanya during all times. The dotted lines indicate the 21-month and 8.4-month periods, respectively. The dash-dotted lines indicate the 30-month period. The LS results greater than 0.14 at $\mathrm{MH}, 0.18$ at $\mathrm{BJ}, 0.28$ at $\mathrm{WH}$, and 0.34 at SY in the zonal wind have a 95\% confidence level. Correspondingly, in the meridional wind, those numbers are 0.16 at $\mathrm{MH}, 0.19$ at BJ, 0.28 at $\mathrm{WH}$, and 0.33 at SY. The intensity of the area surrounded by the solid lines is above the significance level.

LS periodogram of the diurnal tidal amplitudes of the meridional and zonal winds at the Beijing, Wuhan, and Sanya stations. The figure shows that the QBO signals are significant in both zonal and meridional winds over Wuhan at approximately 3.5 to 4.0 $\mathrm{m} / \mathrm{s}$, strong in meridional component over Sanya at approximately $6 \mathrm{~m} / \mathrm{s}$, and a little weak in zonal component over Sanya at approximately $2.5 \mathrm{~m} / \mathrm{s}$, but this QBO oscillation is very weak over Beijing at approximately 1.0 to $1.5 \mathrm{~m} / \mathrm{s}$.

Combining the seasonal variation and LS spectrum for 6DW amplitudes over each station, these features correspond well at all altitudes. For example, in the zonal wind over Wuhan, the QBO signal in diurnal tidal amplitudes is approximately 3 to $4 \mathrm{~m} / \mathrm{s}$ between 82 and $94 \mathrm{~km}$ in Figure 7b, and in Figure $5 c$, the AO signal in 6DW amplitudes appears mainly between 94 to $100 \mathrm{~km}$ and 80 to $82 \mathrm{~km}$; therefore, the seasonal feature of $6 \mathrm{DW}$ amplitudes in zonal wind over Wuhan exists only at 94 to $100 \mathrm{~km}$ and $82 \mathrm{~km}$ in Figure 4c. In the meridional wind over Wuhan, the QBO signal in diurnal tidal amplitudes is significant in Figure 7e, so the seasonal feature of $6 \mathrm{DW}$ is very weak in Figure $4 \mathrm{~g}$, and the 21 -month and 8.4-month periods are strong in Figure $5 \mathrm{~g}$. In the zonal wind over Sanya, the QBO signal in the diurnal tidal amplitudes appeared at approximately $95 \mathrm{~km}$ and $82 \mathrm{~km}$ in Figure 7c; correspondingly, the 8.4-month period is significant at these altitudes in Figure $5 \mathrm{~d}$. Similarly, the $\mathrm{QBO}$ signal is very strong in the meridional wind over Sanya in Figure 7f, which leads to the reduction in seasonal fea- tures under $92 \mathrm{~km}$ in Figure $4 \mathrm{~h}$. The above discussion can explain why the $\mathrm{QBO}$ oscillation in diurnal tidal amplitudes modulates the $\mathrm{AO}$ in $6 \mathrm{DW}$ amplitudes over Wuhan and Sanya, shifting them into 21-month and 8.4-month period variations, thereby weakening the seasonal features at the corresponding altitudes.

Moreover, although the QBO in the horizontal wind cannot modulate the $\mathrm{AO}$ in $6 \mathrm{DW}$ amplitudes, it can directly modulate the $6 \mathrm{DW}$ amplitudes in the mesopause region (Huang YY et al., 2017). For instance, the QBO signal, which has an approximately 29-month period in the zonal wind over Wuhan, clearly exists between 82 and $94 \mathrm{~km}$ in Figure $6 \mathrm{~b}$, and in Figure $5 \mathrm{c}$, the QBO signal, with an approximately 30 -month period in 6DW amplitudes mainly appears at the same altitudes. At the Sanya station, the QBO signal, with an approximately 27 to 31 -month period, is approximately $2.3 \mathrm{~m} / \mathrm{s}$ in the meridional wind at altitudes from 90 to $94 \mathrm{~km}$ in Figure 6f, so the QBO signal, with an approximately 29-month period in the $6 \mathrm{DW}$ amplitudes exists also in the meridional component from 90 to $96 \mathrm{~km}$ in Figure $5 \mathrm{~g}$. There is no significant QBO signal in the amplitudes of the zonal component of 6DW over Sanya in Figure $5 \mathrm{~d}$, which is similar to Figure $6 \mathrm{c}$. The intensive $\mathrm{QBO}$ variation in the amplitudes of the meridional component of 6DW over Wuhan cannot be explained by the modulation of the $\mathrm{QBO}$ in horizontal wind, which may be related to the $\mathrm{QBO}$ signal in other mechanisms, such as diurnal tidal amplitudes or winds at lower altitudes. 


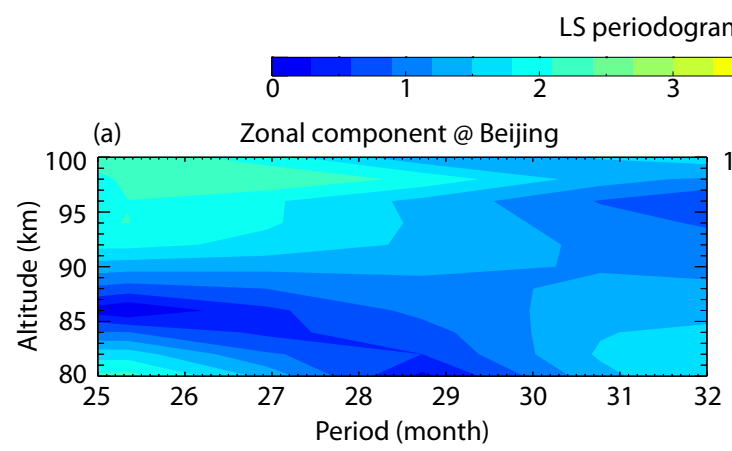

$(\mathrm{m} / \mathrm{s})$

(b)

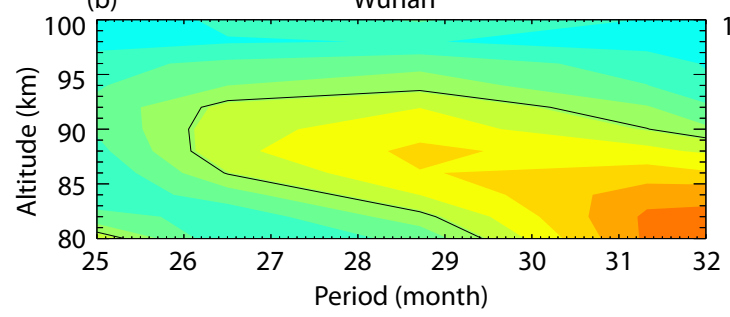

(c)

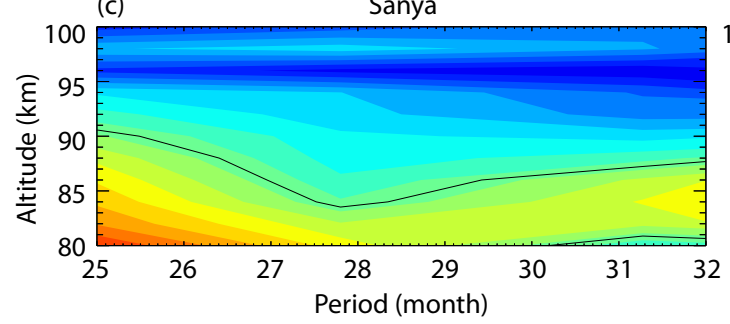

(d) Meridional component @ Beijing

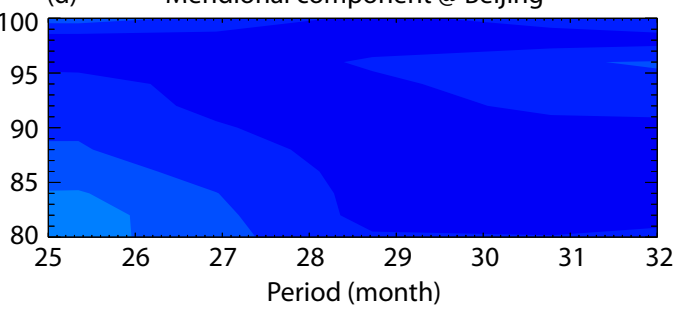

(e)

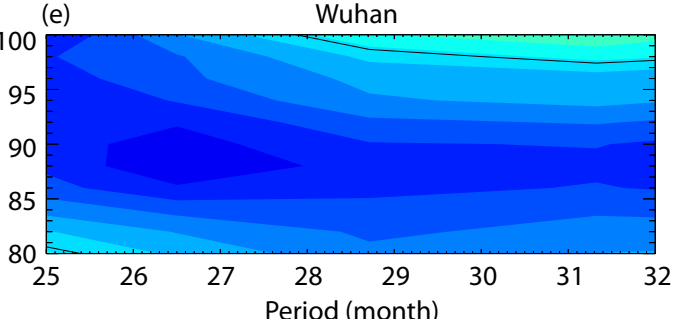

(f)

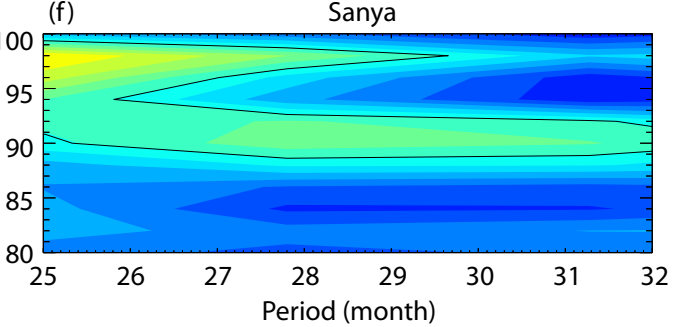

Figure 6. Lomb-Scargle periodogram of the daily mean winds in the zonal component (left column, a to $\mathrm{c}$ ) and the meridional component (right column, $d$ to $f$ ) in Beijing, Wuhan, and Sanya. The LS results greater than $2.3 \mathrm{~m} / \mathrm{s}$ at BJ, $2.1 \mathrm{~m} / \mathrm{s}$ at WH, and $2.4 \mathrm{~m} / \mathrm{s}$ at SY in the zonal wind have a $95 \%$ confidence level. Correspondingly, in the meridional wind, those numbers are $1.3 \mathrm{~m} / \mathrm{s}$ at BJ, $1.4 \mathrm{~m} / \mathrm{s}$ at WH, and $1.9 \mathrm{~m} / \mathrm{s}$ at SY.

The previous discussion about the QBO modulated AO being a 21month or 8.4-month period has focused on the 6DW amplitude at middle and low latitudes; we would now move on to the features of the high-latitude 6DW amplitude. On the other hand, we have discussed the modulation of 6DW amplitudes and their features at different latitudes by interannual variations such as AO and SAO. Next, we study the modulation of some short-period variations on the 6DW amplitudes.

\subsection{Twenty-Seven-Day Period in the 6DW Amplitudes}

For short-period variations, we are interested in the solar rotation variation, which has a period of approximately 27 days. Lean (1991) suggested that the solar rotational period could vary from 25 days to 35 days depending on the solar latitude. In this study, we use the term ' 27 days' to describe the variations in the period of 25 to 29 days, which may be related to variations in the solar rotation. Figure 8 shows the normalized LS spectra periodogram over the four stations within the zonal and meridional 6DW amplitudes. The figure shows that there is a significant 26-day period in the LS spectrum of the meridional wind over Mohe. However, these solar rotation variations near the 27-day period are weaker in the zonal wind at Mohe station. Over Beijing and Wuhan, we found a strong 26- to 27-day period in both the LS spectrum of the zonal and meridional 6DW amplitudes. At Sanya station, no significant solar rotation variation observed in either the meridional or zonal 6DW amplitudes.
Figure 9 shows the wavelet spectrum near the 27-day period from 8 December 2008 to 26 November 2017 at $90 \mathrm{~km}$ over the Beijing station. From this wavelet spectrum, it can be seen that from June 2015 to June 2016, the 27-day variation is the stronger over Beijing during the period - from August 1, 2011 to November 26, 2017 - when all of the 3 meteor radars, Beijing, Wuhan, and Mohe, observed wind data. Although the most intensive 27-day variation in the amplitudes of the zonal component of 6DW over Beijing is from March to May 2013, we choose the period from 2015 June to 2016 June, considering that the 27-day variation over Beijing in the amplitudes of both the zonal and meridional components of 6DW is stronger in this period.

According to the result from Figure 9, we select the time period from June 2015 to June 2016 to obtain the LS spectrum near the 27-day variation in 6DW amplitude in Mohe, Beijing, and Wuhan. Figure 10 shows the Lomb-Scargle periodogram of the 6DW amplitudes in the zonal and meridional winds near the 27-day period at Mohe, Beijing, and Wuhan from June 2015 to June 2016. As shown in Figure 10, the 27-day period can be seen clearly at the 3 stations. The 27-day period at the Beijing station in the amplitudes of the zonal component of 6DW is significantly stronger than in the amplitudes of the meridional component of 6DW, while the 27-day period in the amplitudes of the meridional component at the Mohe station is slightly stronger than in the zonal component; the LS spectrum of 6DW amplitudes in the zonal wind at the Wuhan station also has a nearly 27-day variation. 

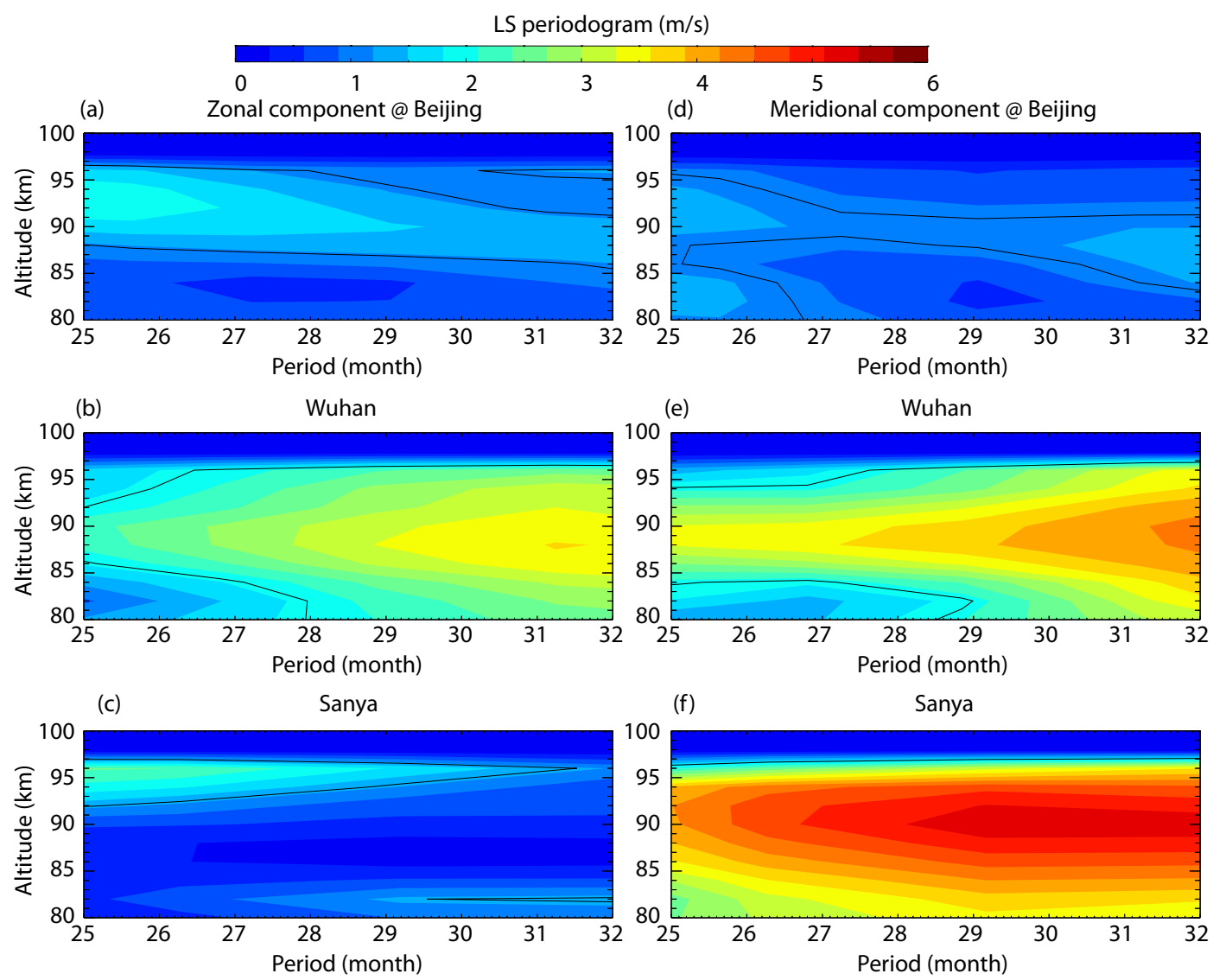

Figure 7. Lomb-Scargle periodogram of diurnal tidal amplitudes in the zonal component (left column, a to c) and the meridional component (right column, $d$ to $\mathrm{f}$ ) in Beijing, Wuhan, and Sanya. The LS results greater than $1.1 \mathrm{~m} / \mathrm{s}$ at BJ, $1.1 \mathrm{~m} / \mathrm{s}$ at WH and $1.2 \mathrm{~m} / \mathrm{s}$ at SY in the zonal wind are at the $95 \%$ confidence level. Correspondingly, those numbers are $0.98 \mathrm{~m} / \mathrm{s}$ at BJ, $1.2 \mathrm{~m} / \mathrm{s}$ at WH and $1.6 \mathrm{~m} / \mathrm{s}$ at SY for the meridional wind.

Combining the 27-day variation in 6DW amplitudes at all 3 meteor radars, we can see that, as the latitude increases, the 27-day variation gradually shifts from the zonal component (eastward) to the meridional component (northward) in the LS spectrum.

Moreover, by focusing on only the zonal wind, we find that the 27-day variation in 6DW amplitudes is more significant over Wuhan than over other latitudes. According to the order of the 27-day variation intensities from strong to weak, the sequence of stations is Wuhan, Beijing, and Mohe. In the meridional wind, the 27-day variation is strongest over Mohe, and is weak over Beijing and Wuhan.

\section{Summary}

Mesopause horizontal winds observed by a meteor radar chain are used to investigate the climatology of the mesopause quasi-6day wave. The neutral wind data were from December 4, 2008 to November 26, 2017, and these data involved 4 meteor radars, namely, the Mohe station $\left(53.5^{\circ} \mathrm{N}, 122.3^{\circ} \mathrm{E}\right)$ located at a mid-highlatitude area; the Beijing $\left(40.3^{\circ} \mathrm{N}, 116.2^{\circ} \mathrm{E}\right)$ and Wuhan $\left(30.6^{\circ} \mathrm{N}\right.$, $\left.114.4^{\circ} \mathrm{E}\right)$ meteor radars located in the middle latitudes; and the Sanya station $\left(18.3^{\circ} \mathrm{N}, 109.4^{\circ} \mathrm{E}\right)$ located at a low latitude. The $6 \mathrm{DW}$ amplitudes obtained from these 4 meteor radars exhibit significant seasonal and latitudinal variations.

The monthly mean 6DW amplitudes in the meridional wind are weaker than those in the zonal wind. At these 4 stations, the largest 6DW amplitudes are approximately $17 \mathrm{~m} / \mathrm{s}$ in the zonal wind and approximately $13 \mathrm{~m} / \mathrm{s}$ in the meridional wind. In general, 6DW amplitudes are strongest from July to October and weakest from January to February, but at Wuhan station, there is no significant seasonal feature. The seasonal variation in 6DW amplitudes is controlled by $\mathrm{AO}$ and $\mathrm{SAO}$. However, $\mathrm{AO}$ is modulated by QBO oscillation during the diurnal tide in other periods at the mid-low latitudes over Wuhan and Sanya stations, thereby weakening the seasonal variation in 6DW amplitudes.

Moreover, for short-period features, we are interested in the solar rotation variation near the 27-day period. At midlatitudes over Wuhan, Beijing, and Mohe, the 6DW amplitudes are significantly modulated by the 27-day variation. From Wuhan to Mohe, the 27day variation shifts from modulating primarily the zonal component of the 6DW amplitudes to modulating primarily the meridional component, as well.

\section{Acknowledgments}

We appreciate the use of the meteor radar data provided by the Chinese Meridian Project and STERN (the Solar-Terrestrial Environment Research Network, http://www.stern.ac.cn). This work was supported by the National Natural Science Foundation of China (41774158, 41974174, 41674150, 41831071 and 41904135) and the Open Research Project of Large Research Infrastructures of 


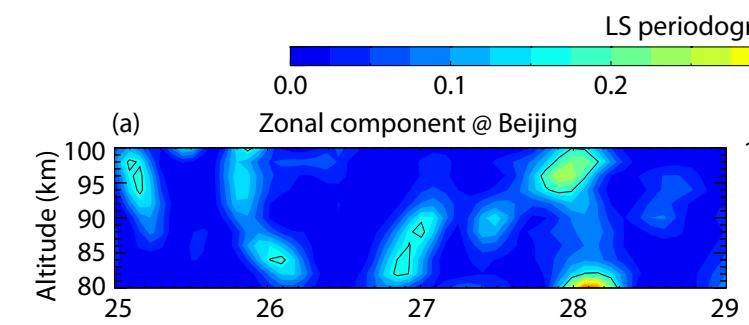

$0.3 \quad 0.4 \quad 0.5$
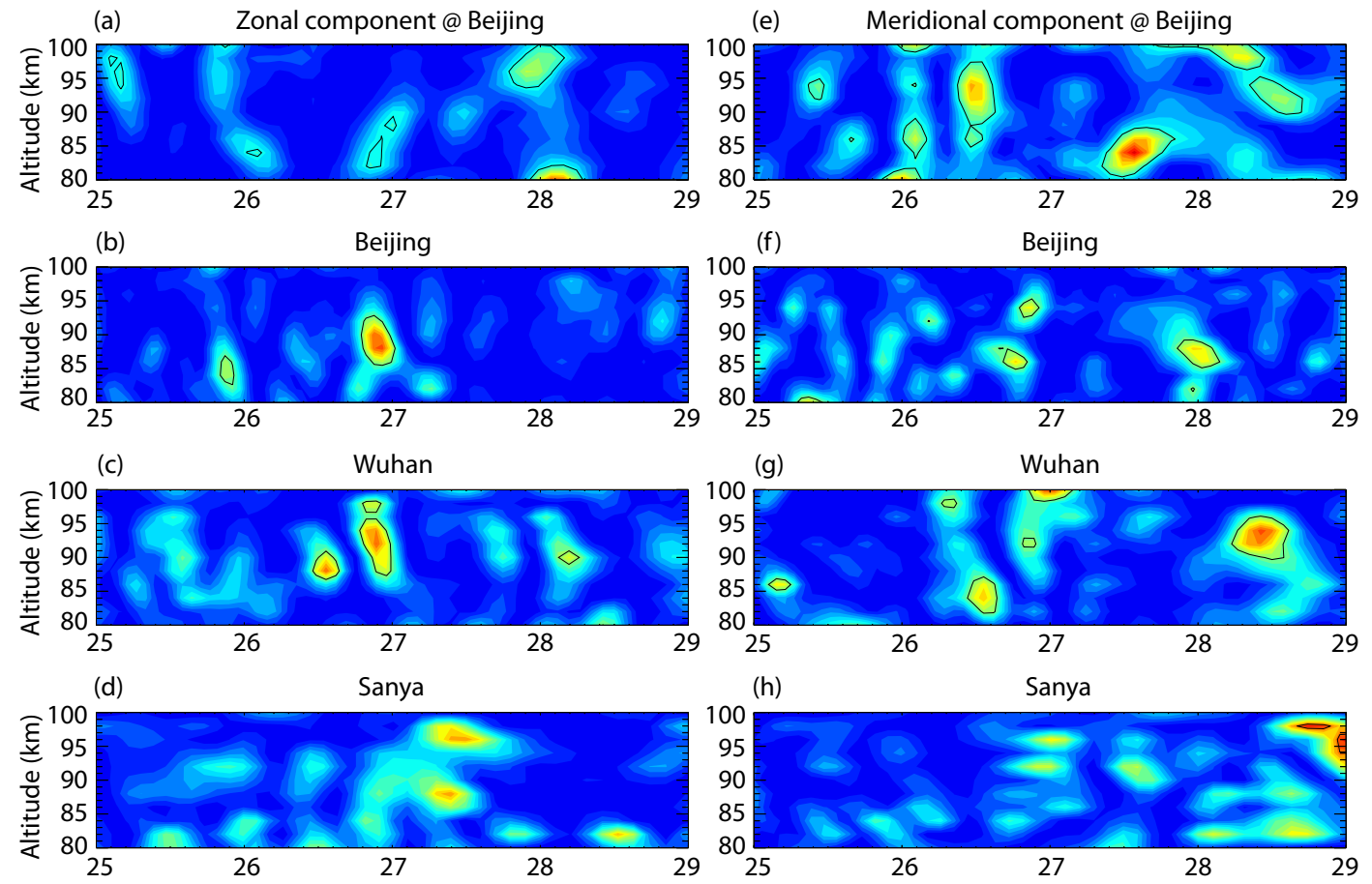

Figure 8. Normalized Lomb-Scargle periodogram of the 6DW amplitudes in the zonal component (left column, a to d) and the meridional component (right column, e to h) near the 27-day period at Mohe, Beijing, Wuhan, and Sanya. The LS results greater than 0.14 at $\mathrm{MH}, 0.17$ at BJ, 0.28 at $\mathrm{WH}$, and 0.33 at SY in the zonal wind are at the $95 \%$ confidence level. Correspondingly, for the meridional wind, those numbers are 0.16 at $\mathrm{MH}, 0.19$ at $\mathrm{BJ}, 0.28$ at $\mathrm{WH}$, and 0.32 at SY.
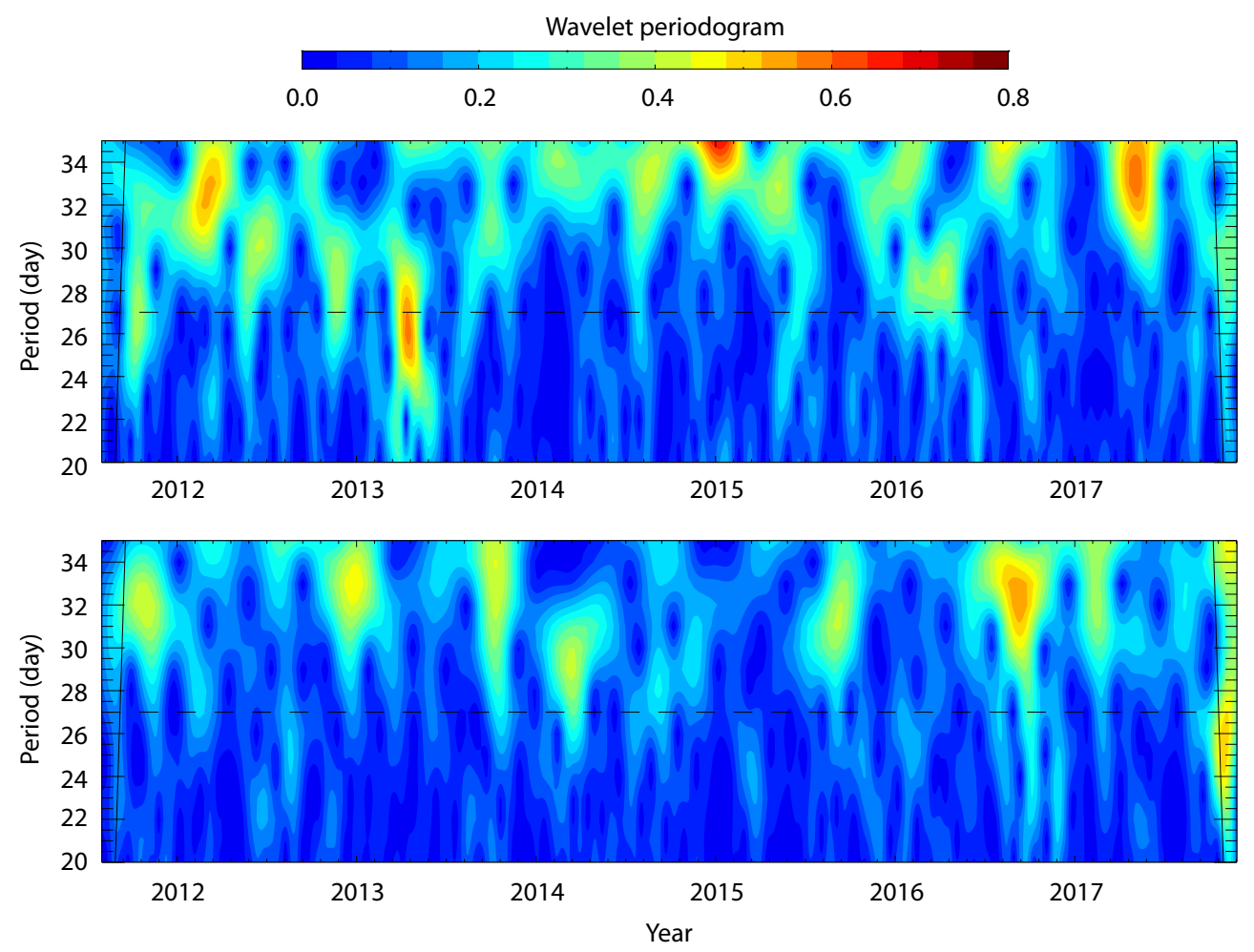

Figure 9. Normalized wavelet spectrum near the 27-day period from 1 August 2011 to 26 November 2017 at $90 \mathrm{~km}$ over the Beijing station. The dotted lines indicate the 27-day period. 

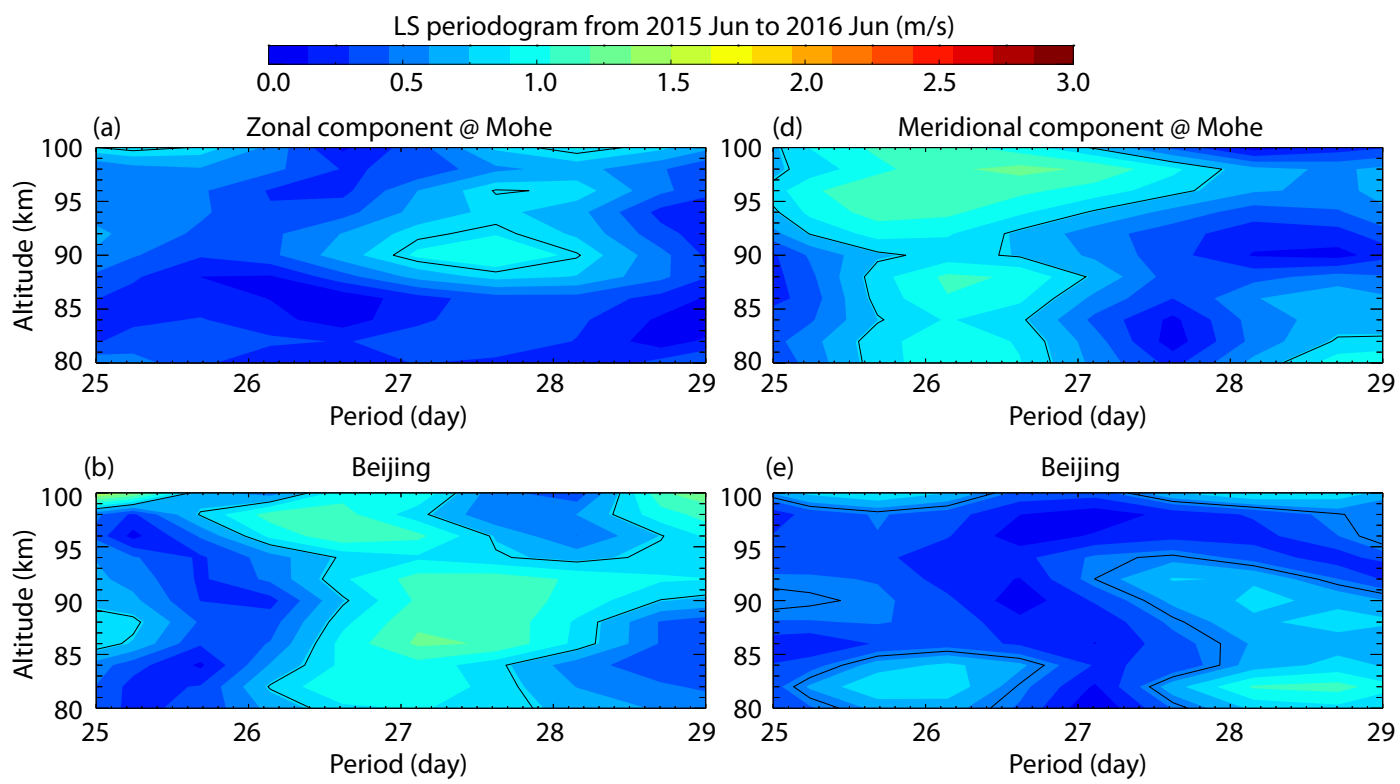

(e) Beijing
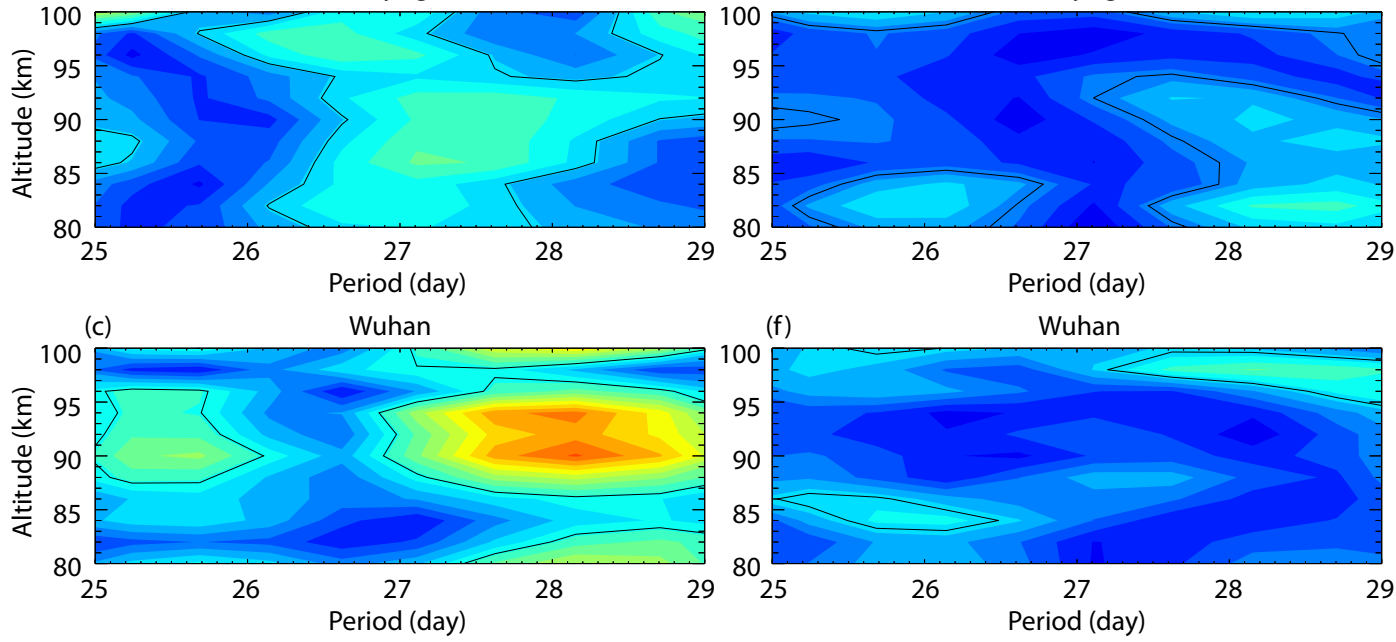

Figure 10. Lomb-Scargle periodogram of the 6DW amplitudes in the zonal component (left column, a to c) and the meridional component (right column, $d$ to f) near the 27-day period at Mohe, Beijing, and Wuhan from June 2015 to June 2016. The LS results greater than $0.79 \mathrm{~m} / \mathrm{s}$ at $\mathrm{MH}, 0.72 \mathrm{~m} / \mathrm{s}$ at BJ and $0.95 \mathrm{~m} / \mathrm{s}$ at $\mathrm{WH}$ in the zonal wind are at a $95 \%$ confidence level. Correspondingly, for the meridional wind, the numbers are $0.71 \mathrm{~m} / \mathrm{s}$ at $\mathrm{MH}, 0.49 \mathrm{~m} / \mathrm{s}$ at $\mathrm{BJ}$ and $0.76 \mathrm{~m} / \mathrm{s}$ at $\mathrm{WH}$.

CAS - "Study on the interaction between low/mid-latitude atmosphere and ionosphere based on the Chinese Meridian Project".

\section{References}

Andrews, D. G., Holton, J. R., and Leovy, C. B. (1987). Middle Atmosphere Dynamics (pp. 489). San Diego, Calif: Academic.

Belova, A., Kirkwood, S., Murtagh, D., Mitchell, N., Singer, W., and Hocking, W. (2008). Five-day planetary waves in the middle atmosphere from Odin satellite data and ground-based instruments in Northern Hemisphere summer 2003, 2004, 2005 and 2007. Ann. Geophys., 26(11), 3557-3570. https://doi.org/10.5194/angeo-26-3557-2008

Forbes, J. M. (2000). Wave coupling between the lower and upper atmosphere: case study of an ultra-fast Kelvin Wave. J. Atmos. Sol. -Terr. Phys., 62(17-18), 1603-1621. https://doi.org/10.1016/s1364-6826(00)00115-2

Forbes, J. M., and Zhang, X. L. (2017). The quasi- 6 day wave and its interactions with solar tides. J. Geophys. Res.-Space Phys., 122(4), 4764-4776. https://doi.org/10.1002/2017ja023954

Franke, S. J., Chu, X., Liu, A. Z., and Hocking, W. K. (2005). Comparison of meteor radar and $\mathrm{Na}$ Doppler lidar measurements of winds in the mesopause region above Maui, Hawaii. J. Geophys. Res.-Atmos., 110(D9), D09S02. https://doi.org/10.1029/2003jd004486

Gan, Q., Wang, W. B., Yue, J., Liu, H. L., Chang, L. C., Zhang, S. D., Burns, A., and $\mathrm{Du}$, J. A. (2016). Numerical simulation of the 6 day wave effects on the ionosphere: Dynamo modulation. J. Geophys. Res.-Space Phys., 121(10), 10103-10116. https://doi.org/10.1002/2016ja022907

Garcia, R. R., Lieberman, R., Russell III, J. M., and Mlynczak, M. G. (2005). Largescale waves in the mesosphere and lower thermosphere observed by
SABER. J. Atmos. Sci., 62(12), 4384-4399. https://doi.org/10.1175/jas3612.1 Geisler, J. E., and Dickinson, R. E. (1976). The five-day wave on a sphere with realistic zonal winds. J. Atmos. Sci., 33(4), 632-641. https://doi.org/10.1175/1520-0469(1976)033<0632:Tfdwoa>2.0.Co;2

Gong, Y., Li, C., Ma, Z., Zhang, S. D., Zhou, Q. H., Huang, C. M., Huang, K. M., Li, G. Z., and Ning, B. Q. (2018). Study of the quasi-5-day wave in the MLT region by a meteor radar chain. J. Geophys. Res.-Atmos., 123(17), 9474-9487. https://doi.org/10.1029/2018jd029355

Gu, S. Y., Ruan, H. B., Yang, C. Y., Gan, Q., Dou, X. K., and Wang, N. N. (2018). The morphology of the 6-day wave in both the neutral atmosphere and $F$ region ionosphere under solar minimum conditions. J. Geophys. Res.-Space Phys., 123(5), 4232-4240. https://doi.org/10.1029/2018ja025302

Hocking, W. K., Fuller, B., and Vandepeer, B. (2001). Real-time determination of meteor-related parameters utilizing modern digital technology. J. Atmos. Sol. -Terr. Phys., 63(2-3), 155-169. https://doi.org/10.1016/s13646826(00)00138-3

Holdsworth, D. A., Reid, I. M., and Cervera, M. A. (2004). Buckland Park all-sky interferometric meteor radar. Radio Sci., 39(5), RS5009. https://doi.org/10.1029/2003rs003014

Huang, Y. Y., Zhang, S. D., Li, C. Y., Li, H. J., Huang, K. M., and Huang, C. M. (2017). Annual and interannual variations in global 6.5DWs from 20 to $110 \mathrm{~km}$ during 2002-2016 observed by TIMED/SABER. J. Geophys. Res.-Space Phys., 122(8), 8985-9002. https://doi.org/10.1002/2017ja023886

Jiang, G., Xiong, J., Wan, W., Ning, B., and Liu, L. (2008a). Observation of 6.5-day waves in the MLT region over Wuhan. J. Atmos. Sol. -Terr. Phys., 70(1), 41-48. https://doi.org/10.1016/j.jastp.2007.09.008

Jiang, G., Xu, J. Y., Xiong, J., Ma, R., Ning, B., Murayama, Y., Thorsen, D., Gurubaran, S., Vincent, R. A., ... Franke, S. J. (2008b). A case study of the 
mesospheric 6.5-day wave observed by radar systems. J. Geophys. Res.Atmos., 113(D16), D16111. https://doi.org/10.1029/2008jd009907

Lean, J. (1991). Variations in the sun's radiative output. Rev. Geophys., 29(4), 505-535. https://doi.org/10.1029/91rg01895

Li, G. Z., Ning, B. Q., Li, A., Yang, S. P., Zhao, X. K., Zhao, B. Q., and Wan, W. X. (2018). First results of optical meteor and meteor trail irregularity from simultaneous Sanya radar and video observations. Earth Planet. Phys., 2(2), 15-21. https://doi.org/10.26464/epp2018002

Lieberman, R. S., Riggin, D. M., Franke, S. J., Manson, A. H., Meek, C., Nakamura, T., Tsuda, T., Vincent, R. A., and Reid, I. (2003). The 6.5-day wave in the mesosphere and lower thermosphere: Evidence for baroclinic/barotropic instability. J. Geophys. Res.-Atmos., 108(D20), 4640. https://doi.org/10.1029/2002jd003349

Liu, H. L., Talaat, E. R., Roble, R. G., Lieberman, R. S., Riggin, D. M., and Yee, J. H. (2004). The 6.5-day wave and its seasonal variability in the middle and upper atmosphere. J. Geophys. Res.-Atmos., 109(D21), D21112. https://doi.org/10.1029/2004jd004795

Liu, H. L., Wang, W., Richmond, A. D., and Roble, R. G. (2010). lonospheric variability due to planetary waves and tides for solar minimum conditions. J. Geophys. Res.-Space Phys., 115(A6), A00G01. https://doi.org/10.1029/2009ja015188

Lomb, N. R. (1976). Least-squares frequency analysis of unequally spaced data. Astrophys. Space Sci., 39(2), 447-462. https://doi.org/10.1007/bf00648343

Meyer, C. K., and Forbes, J. M. (1997). A 6.5-day westward propagating planetary wave: Origin and characteristics. J. Geophys. Res.-Atmos., 102(D22), 26173-26178. https://doi.org/10.1029/97jd01464

Miyoshi, Y., and Hirooka, T. (1999). A numerical experiment of excitation of the 5-day wave by a GCM. J. Atmos. Sci., 56(11), 1698-1707. https://doi.org/10.1175/1520-0469(1999)056<1698:Aneoeo>2.0.Co;2
Miyoshi, Y., and Hirooka, T. (2003). Quasi-biennial variation of the 5-day wave in the stratosphere. J. Geophys. Res.-Atmos., 108(D19), 4620. https://doi.org/10.1029/2002jd003145

Riggin, D. M., Liu, H. L., Lieberman, R. S., Roble, R. G., Russell III, J. M., Mertens, C. J., Mlynczak, M. G., Pancheva, D., Franke, S. J., ... Vincent, R. A. (2006). Observations of the 5-day wave in the mesosphere and lower thermosphere. J. Atmos. Sol. -Terr. Phys., 68(3-5), 323-339. https://doi.org/10.1016/j.jastp.2005.05.010

Salby, M. L. (1981). Rossby normal modes in nonuniform background configurations. Part II. Equinox and solstice conditions. J. Atmos. Sci., 38(9), 1827-1840. https://doi.org/10.1175/15200469(1981)038<1827:Rnminb >2.0.Co;2

Salby, M. L. (1984). Survey of planetary-scale traveling waves: the state of theory and observations. Rev. Geophys., 22(2), 209-236. https://doi.org/10.1029/RG022i002p00209

Scargle, J. D. (1982). Studies in astronomical time series analysis. II . statistical aspects of spectral analysis of unevenly spaced data. Astrophys. J., 263(2), 835-853. https://doi.org/10.1086/160554

Talaat, E. R., Yee, J. H., and Zhu, X. (2001). Observations of the 6.5-day wave in the mesosphere and lower thermosphere. J. Geophys. Res.-Atmos., 106(D18), 20715-20723. https://doi.org/10.1029/2001jd900227

Wu, D. L., Hays, P. B., and Skinner, W. R. (1994). Observations of the 5-day wave in the mesosphere and lower thermosphere. Geophys. Res. Lett., 21(24), 2733-2736. https://doi.org/10.1029/94gl02660

Yi, W., Xue, X. H., Reid, I. M., Murphy, D. J., Hall, C. M., Tsutsumi, M., Ning, B. Q., Li, G. Z., Vincent, R. A., ... Dou, X. K. (2019). Climatology of the mesopause relative density using a global distribution of meteor radars. Atmos. Chem. Phys., 19(11), 7567-7581. https://doi.org/10.5194/acp-19-7567-2019 